\title{
Duas histórias de migrantes sobre educação, trabalho e moradia na periferia paulistana (1960 e 1980)
}

\author{
Adriana Santiago Rosa Dantas *
}

A cidade de São Paulo recebeu um grande fluxo de migrantes oriundos do Nordeste a partir da primeira metade do século XX. As condições materiais com que tais migrantes chegaram ao Sudeste ainda refletem a dificuldade de inserção na cidade, no que diz respeito ao mundo do trabalho e à educação (ARAÚJO \& CODES, 2012). Tais condições podem ser apreendidas como a baixa escolarização, pouca ou nenhuma qualificação profissional, a localização de origem, isto é, provenientes de regiões rurais, bem como o conjunto de recursos culturais e materiais. Alguns estudos apontam que este afluxo foi acompanhado de preconceito em relação aos nordestinos por causa deste capital cultural. Alguns exemplos dizem respeito às representações sociais, como a "invenção do Nordeste" por parte do Sudeste como um lugar atrasado e de pobreza (ALBUQUERQUE, 2009). Também foi associado o aumento da criminalidade em São Paulo à chegada dos migrantes em alguns bairros da cidade (CALDEIRA, 2003). A chegada de uma mulher nordestina na prefeitura da maior cidade do país foi acompanhada de preconceito, tendo o "escândalo" de sua administração associada à condição de naturalidade da prefeita (PENNA, 1992). Nesta linha, alguns autores também apontam como se propaga esta visão pejorativa através da mídia e de representações cristalizadas de nordestinos como pessoas pobres e sem instrução (PENNA, 1998; SILVA, 2010; 2012).

Por outro lado, autores buscaram desconstruir o entendimento da migração calcado na ideia da grande pobreza da região como sendo o principal fator que desencadeou a vinda dos migrantes para a região Sudeste. Estudos mostram que tal mobilidade foi primeiramente incentivada por interesses econômicos do Estado

\footnotetext{
* Linguista pela Universidade Estadual de Campinas (Unicamp) e Mestre em Estudos Culturais pela Escola de Artes, Ciências e Humanidades da Universidade de São Paulo (EACH-USP).
} 
brasileiro e dos cafeicultores do Sudeste em trazer mão de obra mais barata para as fazendas de café que receberam anteriormente imigrantes para o trabalho. $\mathrm{O}$ procedimento era semelhante ao recebimento dos estrangeiros, inclusive na utilização da Hospedaria dos Imigrantes no bairro do Brás na cidade de São Paulo (PAIVA, 2004). Decorrente deste processo, o agenciamento dos nordestinos alocados em São Paulo permitiu a chegada de muitos outros, vindos não mais pela intervenção de interesses do governo e dos agricultores, mas para trabalhar nas indústrias da capital. Os próprios migrantes criavam redes familiares e fraternais de recebimento de novos nordestinos (FONTES, 2008; GOMES, 2006). Muitos destes migrantes se instalaram na periferia da cidade. Por exemplo, na Zona Leste, uma das periferias de São Paulo, depois da instalação da indústria Nitro Química na década de 1930, o bairro de São Miguel Paulista ficou conhecido como a "Nova Bahia" pela grande quantidade de nordestinos que lá chegaram (FONTES, 1997).

Este artigo visa apresentar resultados parciais de uma pesquisa realizada em um bairro da Zona Leste, Ermelino Matarazzo, vizinho de São Miguel Paulista, que recebeu migrantes nordestinos a partir da década de $1940^{1}$. Por se tratar da análise de um microcosmo, foi possível verificar de forma mais precisa as diferenças de inserção desses migrantes na cidade pela moradia, pelo trabalho e educação, no tempo e no espaço. Para tanto, foi possível relacionar algumas diferenças que passaram tais migrantes no que diz respeito à periferização ${ }^{2}$, a qual é caracterizada pelos loteamentos, autoconstrução, formação de favelas, processo de espoliação urbana na qual os moradores e moradoras da periferia foram submetidos (KOWARICK, 1993; 1997; 2009).

O objetivo do meu estudo foi o de reconstruir a configuração social de Ermelino Matarazzo, que passou por uma grande densidade demográfica a partir de 1940, quando a primeira indústria foi instalada na região, a Celosul, da família Matarazzo. No seu entorno foram vendidos terrenos loteados que muitos trabalhadores adquiriram, principalmente até a década de 1970. No final desta década, começam a surgir as primeiras favelas, visto que os terrenos já estavam muito caros para tais trabalhadores, que começaram a se organizar para ocupar terrenos públicos. Estas duas formas distintas de acesso à moradia foram denominadas de "região dos loteamentos" e "região das ocupações". Foram realizadas dezoito entrevistas com antigos moradores de Ermelino Matarazzo, os quais se instalaram na região de loteamentos e na região de favelas/ocupações. O critério de escolha foi entrevistar os mais antigos que testemunharam o processo de crescimento do distrito a partir da década de 1940. Entrevistá-los permitiu concordar com os dados atuais de como eles chegavam a São Paulo, com pouca escolaridade, em postos de trabalho menos remunerados. Todavia, pela data de chegada foi possível perceber a inserção diferente dos que chegaram mais recentemente, sugerindo que as condições materiais com que chegaram à cidade não foram tão determinantes quanto os fatores sociais externos, como o mercado de trabalho e a especulação imobiliária na periferia, que foram se modificando ao longo do tempo, levando tais migrantes cada vez mais para a precarização (CABANES, 2011) e até o possível motivo de retorno apontado pelos demógrafos no século XXI (OLIVEIRA \& JANNUZZI, 2005). 
Neste trabalho, serão comparadas as histórias de duas nordestinas que chegaram em condições educacionais e sociais parecidas em São Paulo, mas em dois tempos distintos, uma na década de 1960 e a outra na década de $1980^{3}$.

\section{Educação, trabalho e moradia}

A primeira chama-se Dalila 4 . Ela é natural de Inhambupe, no sertão da Bahia. É a caçula de oito irmãos. Em sua infância trabalhava na roça. Não pôde estudar, pois seu pai não permitia. Seus irmãos mais velhos começaram a migrar para São Paulo, até que um deles se acidentou, fazendo com que ela acompanhasse a mãe, já separada de seu pai, para cuidar deste irmão no ano de 1963. Acabou se instalando na cidade e trabalhando como doméstica aos 16 anos. Com o retorno de sua mãe, ficou morando na casa da família em que trabalhava. Conheceu seu marido, também baiano, mas de Salvador, em São Paulo. Seu esposo já conhecia Ermelino Matarazzo, por isso compraram um lote para pagar em oito anos. Durante o namoro foram construindo a casa aos poucos. Em 1972, casaram-se e foram morar em Ermelino Matarazzo. Na época, Dalila trabalhava como doméstica no "bairro nobre" do Ibirapuera. Estudou pouco, o básico para se alfabetizar. Depois foi trabalhar em bufês na Zona Leste. Teve três filhos que estudaram nas escolas públicas no entorno de sua casa. Atualmente, todos são casados e moram em Ermelino. Os dois rapazes completaram o Ensino Médio, o mais velho é gerente geral em uma drogaria e o outro é recepcionista contratado pela Prefeitura de São Paulo. A filha caçula é psicóloga e passou em concurso público para trabalhar na Fundação Casa. Dalila tem três netos e um bisneto recém-nascido por parte do filho mais velho e um neto recém-nascido da filha caçula.

A segunda é Zilda, natural de Pernambuco. Trabalhava na roça juntamente com seus outros dez irmãos. Seus pais morreram cedo. À medida que seus irmãos foram casando, ficou apenas ela de solteira. Um dos irmãos que morava em São Paulo, em Ermelino Matarazzo, trouxe Zilda para a capital em 1980 quando ela tinha 28 anos. Teve muita dificuldade para conseguir emprego de doméstica naquela época. Chegou analfabeta e estudou na capital até a terceira série do antigo primário, mas teve de parar por conta do trabalho. Conheceu seu esposo, também migrante, morador de Ermelino, logo depois de conseguir um emprego em casa de família no "bairro nobre" do Morumbi. Em pouco tempo se casaram. Primeiramente, moraram em um barraco na antiga favela Santa Inês, até construir sua casa de alvenaria, conforme a favela se regulamentava. Quando o segundo filho chegou, continuou trabalhando como dona de casa. Todos os seus filhos estudaram na escola pública da região. Eles já estão casados. Agora Zilda vive apenas com o esposo. Um filho é segurança em uma escola privada na Zona Sul e a filha é auxiliar de serviços gerais em escola da Zona Leste. Os dois moram na comunidade e têm filhos pequenos.

As duas chegaram a São Paulo pela influência de irmãos que já haviam se estabelecido. Mesmo assim, pode-se notar que a permanência se deu pela intenção de mobilidade social. Dalila rememora o seguinte: 
Eu não tive estudo. Meu pai era separado e falava que quem estudava naquela época era vagabunda, os piores nomes, imagina! Aqui em São Paulo, eu fazia bico à noite, de dia eu trabalhava na casa de família, e à noite eu ia servir outras casas pra mim ganhar um dinheiro e mandar pra minha mãe que não tinha quem sustentasse. Eu falava: eu não quero isso pra mim, eu vou lutar, eu vou melhorar, eu vou correr atrás, eu não posso ter pena de mim.

Apesar da interdição do seu pai no passado, Dalila em São Paulo estudou o básico para se alfabetizar. Ela via no trabalho a oportunidade de conseguir o bem material que lhe era mais caro, uma casa própria, e o bem simbólico para seus filhos, a educação:

Meu objetivo era ter alguma coisa a mais: eu queria ter uma casa, uma sala, o quarto dos meus filhos, bem arrumadinho, direitinho, como pobre. Queria que minha filha estudasse. Eu não queria o que eu passei, na casa dos outros, eu não queria que nenhum dos meus três filhos passassem. Eu queria que todos estudassem.

Zilda também saiu por influência dos irmãos como no caso de Dalila. A diferença de tempo foi de aproximadamente vinte anos, pois chegou a São Paulo na década de 1980:

Meu irmão me trouxe porque eu fiquei sem pai, sem mãe. Éramos onze irmãos que ficamos sem pai, sem mãe. Foram casando, casando, ficou eu de solteira, aí meu irmão me trouxe pra aqui. Eu vim morar com meus irmãos casados. Cheguei aqui era barraco de tábua.

Dalila relata que não teve muitos problemas para conseguir serviços. Começou em casa de família, trabalhou em postos de serviços de limpeza ou ajudante geral em locais domésticos ou empresas privadas. Nas palavras de Kowarick e Marques: "No momento de mais intenso crescimento da metrópole, tiveram ocasião de trabalhar de forma contínua, com muitas horas extras, pois, até pelo menos 1980, empregos não faltavam nas indústrias ou vários ramos do setor terciário" (KOWARICK \& MARQUES, 2011 , p. 10). Dalila morou muitas vezes no seu trabalho. Já Zilda veio em um contexto diferente, tanto de trabalho, quanto de moradia:

Minha irmã morava aqui, uma amiga e um irmão, o meu cunhado e minha cunhada. Foi aí que eu vim morar com eles. Fiquei muito tempo morando com eles. Teve uma vez, foi uma coisa engraçada. Pra mim foi! Porque eu cheguei aqui, ninguém me queria pra trabalhar porque a gente por 
honesta que for, paga pelos erros dos outros, ninguém me queria pra trabalhar. As minhas irmãs, as minhas cunhadas, que eu vim morar com elas, me levava pra casa das pessoas e dizia: eu conheço você, mas não conheço ela, não vou querer pra trabalhar. E quando eu vim do Norte, quando a gente vem do Norte, não traz nada. Traz apenas quatro pecinhas de roupa, foi o que eu trouxe. Chegou aqui, a mala pegou fogo, queimou minhas roupas tudinho. Aí minha irmã começou a chorar. Como era barraco de tábua, as crianças dela acenderam uma vela e um pedacinho da minha malinha que eu trouxe, desse tamanho, e foram no banheiro. Quando voltaram era fogo, tinha queimado minha mala todinha. A minha irmã começou a chorar, chorar: ah, porque você não tem nada e o que tinha o fogo queimou! Eu disse: eu viro logo índia, [risos] ninguém quer me dar trabalho lá fora, viro logo índia.

Pelo relato de Zilda, pelos pertences pessoais é possível verificar a precariedade material com que ela chegou a São Paulo. Ela nunca tinha estudado no ambiente rural em que vivia em Pernambuco. Seu destino foi a casa da irmã, em barraco de tábua sem luz elétrica, em que conviviam ela, o cunhado, as crianças, o irmão e uma amiga na favela. Nos anos de 1980, ela já não teve a mesma facilidade em conseguir um posto de trabalho como doméstica como as mulheres de sua convivência, muito menos a possibilidade de morar no emprego como Dalila havia feito vinte anos atrás. Mesmo assim, a experiência de migração para Zilda também foi de mobilidade, ao se apropriar de bens culturais:

Porque quando a gente chega do Norte, é aqui que a gente vem abrir o olho. Por sabido que você seja no Norte, se você não é de lá, por muito que você sabe no Norte, parece que aqui em São Paulo é um livro aberto. Aqui quem não sabe ler aprende. Porque meu esposo, quando chegou aqui, ele sempre fez jogo da lotérica, sempre gostou de fazer um joguinho, mas ele não conhecia número, quando ele chegou aqui, que já tá pegando 40 anos que ele tá aqui, ele pega ônibus melhor do que eu, metrô pra qualquer lugar, ônibus bem longe. Aí a gente aprende.

Logo depois conseguiu ocupar-se como doméstica em uma casa no bairro do Morumbi. Em menos de um ano, conheceu seu esposo em Ermelino Matarazzo. Assim como ela, o esposo era nordestino e analfabeto. Pelo seu relato, a compra de sua "casa própria" foi assim: "Meu esposo comprou um pedacinho de chão e fez um barraquinho e foi construindo, aí fez a casa. Mas comprou um pedacinho de chão, uma casinha de madeira".

No período de compra do terreno, na década de 1980, já não era possível apenas "invadir" um espaço na antiga Favela Santa Inês, era preciso comprar um terreno ou barraco. Mais tarde, a favela foi se regularizando e recebendo 
melhorias em infraestrutura. Hoje, a antiga favela é denominada Comunidade Santa Inês. A experiência de compra de Dalila já se deu diferentemente. De certa forma, foi possível fazer certo "planejamento", pois os terrenos na periferia eram mais baratos, a ponto da classe trabalhadora poder comprá-los na década de 1960. Realidade improvável para Zilda em 1980.

$\mathrm{Na}$ época de Dalila, comprar lotes e construir era muito comum. Nas palavras de Kowarick, a autoconstrução era "uma alquimia que serve para reproduzir a força de trabalho a baixos custos para o capital, constitui-se num elemento que acirra ainda mais a dilapidação daqueles que só têm energia física para oferecer a um sistema econômico" (KOWARICK, 1993, p. 65). Dito de outro modo, ela é um processo longo, que se utiliza das redes que a pessoa tem, empregando as forças do trabalhador no seu tempo ocioso para ser realizado, dependente também da capacidade de poupar do proprietário para injetar os recursos na construção. Um dos caminhos para conseguir os recursos para compra de terrenos era por meio de indenização. Antes de se decretar o Fundo de Garantia por Tempo de Serviço, o FGTS, que aconteceu em 1966 (BRASIL, 1990), o funcionário ganhava estabilidade após dez anos trabalhados. Dalila comprou seu terreno com a ajuda do esposo, que era operário e se beneficiou deste tipo de indenização. Seu terreno foi comprado em 1965 e concluíram a obra em 1972:

Eu comprei o meu terreno, nós dois compramos. Tem quarenta anos que eu comprei aqui. Era tudo mato, mato, mato! Não tinha água, era água de poço, a rua tudo de terra. Ele morava aqui em Ermelino. Ele foi numa imobiliária e viu que estava vendendo. Aí juntou nós dois e compramos. $\mathrm{E}$ parcelamos em oito anos pra pagar. Aí a gente foi pagando. Quando estava perto do casamento, ainda levou um ano pagando. Mas quando já estava perto pra casar, como era tudo aberto, não tinha muro, era tudo matagal, os moleques derrubaram toda a casa. Aí nós construímos de novo. Sempre eu falava pra ele: vamos na luta, nós temos tudo. Eu sempre fui uma pessoa muito assim, nós temos tudo, nós temos braço, perna, tudo, então nós temos que ir à luta. Não vamos nos fazer de coitado. Meu marido é uma pessoa que desiste rápido e eu sou uma pessoa, assim, de luta. Ele trabalhou em firmas muito grandes, ele trabalhou na Mercedez ${ }^{5}$, ele trabalhou na Cummins ${ }^{6}$, ele trabalhou na Filizola ${ }^{7}$, tudo firmas muito grandes, mas ele sempre teve um objetivo sempre diferente de mim, ele sempre falava assim, pra mim, eu tendo um barraco, arroz, feijão e farinha, tá bom, só que a minha ambição não era, meu objetivo não era esse, era eu ter alguma coisa a mais, eu queria ter uma casa, uma sala, o quarto dos meus filhos, bem arrumadinho, direitinho, como pobre, queria que minha filha estudasse, eu não queria o que eu passei na casa dos outros, eu não queria que nenhum dos meus três filhos passassem. 
Como Dalila relata, seu esposo havia trabalhado em boas indústrias, como as citadas, pois como já foi dito, antes da década de 1980, muitos migrantes conseguiam postos de trabalhos no setor industrial, principalmente. Isto já não foi possível para o esposo de Zilda, que já estava em uma situação mais precária no distrito.

O processo de autoconstrução foi árduo para Dalila. No entanto, depois de pronta sua casa, permitiu certa estabilidade familiar, se comparada com a história de Zilda. Para os primeiros, suas preocupações estavam relacionadas aos seus filhos, ao estudo e ao trabalho. Dalila, mesmo com pouca qualificação, pôde "investir", ainda que de forma acidentada, na escolarização dos filhos. Ela apreendeu estratégias novas em educação a partir de diferentes socializações que a nova realidade the proporcionava:

Minha filha era muito inquieta, aí eu levei ela na médica. A médica falou assim, "procura colocar ela em vários cursos". Como eu sempre fui andarina mesmo, comecei a perguntar onde tinha escola de dança. Aí eu coloquei ela. Eu levei ela numa dentista, a dentista falou: "ah! sua filha faz aula de dança, agora tá na hora de colocar ela no inglês, inglês é importante, porque quando ela fizer a faculdade, quando ela se formar, ela precisa falar bem inglês". E foi bom, porque ela foi trabalhar em albergue. Por incrível que pareça, a gente tem uma noção que albergue é só pra morador de rua e não é. O albergue é para vários estrangeiros, vem africanos, coreanos.

No ambiente urbano, o contato com outros profissionais mais escolarizados permitiu que Dalila aprendesse novas estratégias que foram aplicadas na vida de sua filha. Ela constata que foi uma boa escolha dar oportunidade de aprender outro idioma que Ihe foi útil profissionalmente. Sua filha formou-se em Psicologia e trabalha com menores em situação de rua, infratores. Seus outros filhos completaram o Ensino Médio.

Por outro lado, o relato de Zilda indica as dificuldades relacionadas em morar, primeiramente, em um barraco de madeira. A incerteza de ter o barraco derrubado, ou não, pela Prefeitura, era uma constante preocupação. A falta de creche também impediu a continuidade de seu trabalho, obrigando-a a ficar em casa para cuidar de seus filhos. O problema da violência da região em que morava foi muito mais presente em seu relato, o que não apareceu de forma significativa nas memórias de Dalila. Zilda disse o seguinte:

Graças a Deus melhorou muito agora. Agora tá uma benção. A gente que mora aqui dentro, hoje, tem que levantar as mãos prô céu porque aqui tá muito bom. A gente entra aqui a hora que quer. A hora que precisa 
sair daqui ninguém anda correndo com medo aqui não! Graças a Deus, tá uma maravilha aqui em vista do que era antes. Agora a gente chega do serviço uma hora da manhã, duas horas, aqui a gente entra e sai, ninguém mexe com ninguém, graças a Deus!

A situação mais precária de chegada e de jornada de Zilda em relação a Dalila também pode ser vista no destino de seus filhos. Os filhos de Zilda completaram o Ensino Fundamental e trabalham como segurança e ajudante geral, morando ainda na comunidade. No caso de Dalila, a caçula chegou ao Ensino Superior e os outros ao Ensino Médio.

\section{Considerações Finais}

As duas experiências das entrevistadas são indicativos das condições de vida de moradores e moradoras de Ermelino Matarazzo que se instalaram em diferentes áreas do distrito ao longo do tempo. Dalila instalou-se em lotes que foram comprados para construção da casa própria, assim como seus vizinhos mais antigos. No caso de Zilda, ela é um exemplo dos muitos migrantes mais recentes que acabaram se instalando nas favelas, visto que as condições materiais para comprar um terreno tinham mudado nas décadas seguintes. Tanto uma quanto a outra chegaram com nenhuma escolaridade ou qualificação profissional para o ambiente urbano, chegaram solteiras. Dalila nem pôde contar com a ajuda dos irmãos, morando em casas de família. Já Zilda necessitou morar com eles, mesmo em um pequeno barraco, com uma população considerável. Já não era tão simples morar no trabalho. No entanto, a inserção no mundo do trabalho, a partir da década de 1960, permitiu para Dalila um pouco mais de estabilidade proporcionada pela moradia, enquanto Zilda viveu muito tempo na insegurança de estar em um lugar ilegal, fruto de ocupações de terra. O poder de compra de uma doméstica e um operário em 1960, de um modo geral, era bem diferente de seus pares nos anos de 1980, como foi visto no exemplo das duas moradoras de Ermelino Matarazzo. O prolongamento dos estudos dos filhos de cada uma também se diferenciou, pois a prole de Dalila conseguiu maior prolongamento dos estudos e, consequentemente, postos de trabalho diferentes dos de Zilda. Assim, este artigo sinaliza que, apesar de condições materiais e capitais simbólicos parecidos, as condições de inserção de grande parte dos migrantes no distrito de Ermelino Matarazzo foram distintas entre as décadas de 1960 e 1980.

\section{Notas}

1 - Este texto rediscute parte do capítulo 2 da dissertação de mestrado da autora (2013), orientada pela Profa. Dra.Graziela Perosa com financiamento da Capes. Este artigo é uma revisão do trabalho completo publicado nos anais do I Encontro Brasileiro de Pesquisa em Cultura realizado em setembro de 2013 na EACH-USP. 
2 - Processo de incentivar a classe trabalhadora, mesmo que não confessa como política de Estado, à compra de terrenos nas franjas da cidade, resultando em construções irregulares, pois a mesma não pôde se beneficiar de moradias sociais no período. Ver Bonduki, 1994; Mautner 1999; Rolnik, 2003.

3 - Foram escolhidas duas entrevistadas que melhor representavam a discussão levantada neste artigo. Este assunto está ampliado com a apresentação de todos os entrevistados no capítulo 2 da dissertação de Dantas (2013).

4 - Os nomes são fictícios.

5 - "A Mercedes-Benz do Brasil, presente há mais de 50 anos no País, é a maior fabricante de veículos comerciais da América Latina". Fonte: sítio oficial. Disponível em: <http://www. mercedes-benz.com.br/Homeinterna.aspx?categoria=140>. Acesso em: 10 abr. 2013.

6 - "No início da década de 70, seguindo a trajetória de alguns de seus grandes clientes mundiais, entre eles Komatsu e Ford, a norte-americana Cummins Engine Company se instalou no Brasil, atraída por novas oportunidades do mercado brasileiro. A subsidiária brasileira foi constituída legalmente em 1971, sob a razão social de 'Cummins Brasil'”. Fonte: sítio oficial. Disponível em: <http://www.cummins.com.br/cla/quem_somos.php>. Acesso em: 28 fev. 2013.

7 - Filizola Beyond Technology. Indústria de Balanças automotivas, de saúde, de rodoviárias, dentre outras. Disponível em: <http://www.filizola.com.br/home/>. Acesso em: 10 abr. 2013.

\section{Referências}

ALBUQUERQUE Jr., Durval Muniz de. A invenção do nordeste e outras artes. 4a ed., São Paulo: Cortez, 2009.

ARAÚJO, Herton Ellery \& CODES, Ana Luiza Machado de. Como Vivem os Migrantes em São Paulo? Estratificação Social entre Migrantes de Diferentes Naturalidades na Região Metropolitana de São Paulo. In: Castro, Jorge Abrahão de e Araújo, Herton Ellery (orgs.) Situação Social Brasileira: Monitoramento das Condições de Vida 2. Brasília: IPEA, 2012.

BONDUKI, Nabil Georges. Origens da Habitação Social no Brasil. In: Análise Social, vol. XXIX (127), p. 711-732, 1994 (3ㅇ).

BRASIL. Lei n. 8.036, de 11 de maio de 1990. Dispõe sobre o Fundo de Garantia do Tempo de Serviço e dá outras providências. Presidência da República Casa Civil Subchefia para Assuntos Jurídicos. Disponível em: <http://www.planalto.gov.br/ccivil_03/Leis/ L8036consol.htm\#art32>. Acesso em: 20 jul. 2012.

CABANES, Robert. Proletários em meio à tormenta neoliberal. Cabanes, R. [et al.] (orgs). Saídas de Emergência: ganhar/perder a vida na periferia de São Paulo. [Tradução Fernando Ferrone, Cibele Saliba Rizek], São Paulo: Boitempo, 2011.

CALDEIRA, Teresa Pires do Rio. Cidades de Muros: crime, segregação e cidadania em São Paulo. 2a ed. [Trad. Frank de Oliveira e Henrique Monteiro], São Paulo: Ed. 34/Edusp, 2003.

DANTAS, Adriana Santiago Rosa. Por dentro da quebrada: a heterogeneidade social de Ermelino Matarazzo e da periferia. 2013. Dissertação (Mestrado em Estudos Culturais). Escola de Artes, Ciências e Humanidades, Universidade de São Paulo, São Paulo, 2013. Disponível em: <http://www.teses.usp.br/teses/disponiveis/100/100135/tde-29082013230632/pt-br.php>. Acesso em: 25 mar. 2014.

FONTES, Paulo. Um nordeste em São Paulo: trabalhadores migrantes em São Miguel Paulista (1945-66). Rio de Janeiro: Editora FGV, 2008.

FONTES, Paulo. Trabalhadores e cidadãos: Nitro Química: a fábrica e as lutas operárias nos anos 50. São Paulo: Annablume, 1997.

GOMES, Sueli de Castro. Uma inserção dos migrantes nordestinos em São Paulo: o comércio de retalhos. In: Imaginário. USP, vol. 12, n. 13, p.143-169, 2006. 
KOWARICK, Lúcio. A espoliação urbana. 2ạ ed. Rio de Janeiro: Paz e Terra, 1993.

KOWARICK, Lúcio. Espoliação urbana, lutas sociais e cidadania: fatias de nossa história recente. Espaços \& Debates: Revista de Estudos Regionais e Urbanos. São Paulo, Ano XVII, n. 40, 1997.

KOWARICK, Lúcio. Viver em risco: sobre a vulnerabilidade socioeconômica e civil. São Paulo: Editora 34, 2009.

KOWARICK, Lúcio \& MARQUES, Eduardo (orgs.) São Paulo: novos percursos e atores (sociedade, cultura e política) São Paulo: Editora 34; Centro de Estudos da Metrópole, 2011.

MAUTNER, Yvonne. A periferia como fronteira de expansão do capital. In: Deák, Csaba e Schiffer, Sueli Ramos (orgs.) O Processo de Urbanização no Brasil. São Paulo: Editora da Universidade de São Paulo, 1999.

OLIVEIRA, Kleber Fernandes de \& JANNUZZI, Paulo de Martino. Motivos para Migração no Brasil e Retorno ao Nordeste: Padrões Etários, Por Sexo e Origem/Destino. In: São Paulo em Perspectiva, v. 19, n. 4, p. 134-143, out./dez. 2005.

PAIVA, Odair da Cruz. Caminhos Cruzados: migração e construção do Brasil moderno (19301950). Bauru, SP: Edusc, 2004.

PENNA, Maura. O que faz ser nordestino: identidades sociais, interesses e o "escândalo" Erundina. São Paulo: Cortez, 1992.

PENNA, Maura. Relatos de migrantes: questionando as noções de perda de identidade e desenraizamento. In: Signorini, Inês (org.) Língua(gem) e identidade: elementos para uma discussão no campo aplicado. São Paulo: FAPESP Campinas, SP: Mercado de Letras: FAEP/ Unicamp, 1998.

ROLNIK, Raquel. A cidade e a lei: legislação, política urbana e territórios na cidade de São Paulo. 3a. ed. São Paulo: Studio Nobel: Fapesp, 2003.

SILVA, Daniel do Nascimento. Dilma eleita pelos nordestinos? Sobre a circulação de atos de fala violentos. Linguagem em foco, v. 2, p. 29-37, 2010.

SILVA, Daniel do Nascimento. Pragmática da Violência: o nordeste na mídia brasileira. Rio de Janeiro: 7Letras: Faperj, 2012.

\title{
RESUMO
}

Este artigo discute a inserção de migrantes internos na periferia de São Paulo, vindos em condições educacionais e sociais parecidas, mas em tempos distintos, nas décadas de 1960 e 1980. Os dados analisados fazem parte de uma pesquisa realizada em Ermelino Matarazzo, na periferia leste da cidade de São Paulo, que recebeu migrantes nordestinos a partir da década de 1940. No texto, são comparadas duas moradoras, dentre as dezoito entrevistas da pesquisa, analisando-se sua inserção na cidade de São Paulo em relação à educação, trabalho e moradia.

Palavras-chave: migração; São Paulo; inserção social.

\begin{abstract}
This article discusses the integration of internal migrants in the outskirts of São Paulo, arrived in similar social and educational conditions, but at different times, in the 1960s and 1980s. The data analyzed is part of a research conducted in Ermelino Matarazzo, a peripheral district of the Eastern Zone of São Paulo, which received migrants from the 1940s. In the text, two residents are compared among the eighteen survey respondents, to examine the inclusion of them in São Paulo with relation to education, work and housing.
\end{abstract}

Keywords: migration; São Paulo; social inclusion. 